\title{
THE USE OF DIFFERENT LEVELS OF MULTI-ROOM MODELING APPROACH-APPLICATION TO BUILDING POLLUTION TRANSPORT AND EFFICIENCY OF OFF- HOUR VENTILATION
}

\author{
Ahmed Cherif Megri \\ Department of Civil, Architectural and Environmental Engineering, \\ North Carolina A and T State University, NC 27411, Greensboro, USA
}

Received 2014-01-31; Revised 2014-03-04; Accepted 2014-03-25

\begin{abstract}
Several building simulation programs have been developed for design, analysis and prediction of the distribution of temperature, airflow and heat transfer between inside and outside of a building and/or between different zones of the same building. These programs are categorized as mono-zone models, multi-room models, zonal models, Computational Fluid Dynamics (CFD) models and multi-zone models. The number of computer programs continues to increase, each reflecting different objectives and concerns. Some of these computer programs are dedicated to research and others to design and auditing. However, none of the existing computer programs is able to translate automatically various steps of the design process as actually performed by design Architectural Engineering firms. This study addresses different levels of multi-room simulation programs developed through the last four decades. Two case studies using multi-room programs have been exposed to illustrate the appropriate use of various levels of this approach for design and analysis.
\end{abstract}

Keywords: Energy, Simulation, Multi-Room, Multi-Zone, Airflow, Thermal, Integrated Models, Pollutant Transport, Off-Hour Ventilation

\section{INTRODUCTION}

After more than four decades, few energy and load simulation programs, such as TRNSYS, ESP-r and DOE (or its new development eQUEST), initially developed in the 70 's of the last century, are still in use by a large number of researchers and designers in many Architectural Engineering (A-E) design firms. Despite its quality, the most recent program, EnergyPlus (Crawley et al., 2001), is more used, but still not widely used within the industry.

Crawley et al. (2005) contrasted the features and capabilities of about twenty building energy simulation programs, including BLAST 1991, DOE-2.1E (Winkelmann et al., 1993; Reilly et al., 1992), Energy Express, Energy-10, EnergyPlus (Crawley et al., 2001), eQUEST, ESP-r, IDA ICE, HAP, HEED, SUNREL, TRACE and TRNSYS. The information was provided by program developers and users based on the capabilities of these programs in term of zone loads, building envelope, daylighting and solar, infiltration, ventilation and multi-zone airflow and so on. Despite the study's significance, this comparison still does not address the fundamental differences between those programs in terms of simplification used, modeling approach employed and the level of simplification considered and more importantly the level of adequacy of these programs to fit the actual design processes and to solve engineering problems.

The object of this study is to illustrate the appropriate use of different levels of multi-room approach to design and analysis residential and commercial buildings through two case studies. In particular, this study attempts to outline the capabilities of thermal, airflow and integrated multi-room models to transform 
simulation results into relevant design information of building envelope and HVAC systems, in term of energy conservation, thermal comfort and indoor air quality.

\section{MODEL CATEGORIZATION USED IN ENERGY SIMULATION PROGRAMS}

All the building Load and Energy Simulation programs have many aspects in common. Basically, they include different modeling features, such as climate data availability, airflow capabilities (infiltration, ventilation and inter-zonal airflow), thermal capabilities, building envelope, electrical and HVAC systems and equipment, day-lighting and solar, environmental emissions and miscellaneous systems (renewable energy systems, economic evaluation and so on). The thermal part includes heat transfer by conduction, convection and radiation, heat gains due to the presence of occupants and equipment and the storage of heat in the room air and building mass. The complex task of describing the building's thermal zones, walls, internal gains, orientation for solar radiation, is usually accomplished using a preprocessor program.

Motivated by simplification and accuracy, idealization and the objective of adequate representation of the physical phenomena, many approach and software categories have been evolved over decades, starting from the "mono-zone" simplified models to more complex ones, such as "zonal" and "multi-zone" models. Examples of application for these categories of models have been addressed by (Liddament, 1994; Megri et al., 1996). The definition of a zone is different from one approach to another. In multi-room approach, a zone is, in general, a specific room or even a collection of rooms. The whole apartment unit in a residential high-rise building can be represented by a single zone, which corresponds to the definition used in HVAC systems design, in which a zone is defined as a conditioned space under the control of a single thermostat. In zonal or CFD approaches, a zone is a sub-division of a room. In airflow modeling approach, the definition of a zone has been extended to include the HVAC systems, in which a control volume within a ducting system may represent a zone.

Diasty et al. (1993) developed a multi-zone model for air humidity behavior predictions in a multi-room building. Haghighat and $\mathrm{Li}$ (2004) performed a comprehensive comparison and validation of these three multi-zone models, COMIS, CONTAM and ESP-r. An analytical computer tool was developed by (Majali et al., 2005) to simulate a transient periodic heat transfer analysis of non-air-conditioned multi-zone buildings. After the validation of this tool, a comparison of the results between a single zone model and a multi-zone model was conducted and more accurate results were obtained when the multi-zone model was used. Yang et al. (2006) analyzed the nonlinear dynamic behaviors of airflow and natural ventilation in multi-zone buildings. They found that the multi-zone model gave good prediction results in a steady state, while failed in unsteady state situations. Grundwald and Kikkawa (2011), applied a new multi-zone simulation model prototype to investigate heat, air, moisture and pollutants transport in a library building. They demonstrated the enhanced ability of this new multi-zone model to predict and deal with mold risk issues.

\subsection{Mono-Zone Models (One-Zone, Nodal or Single-Zone Thermal and Airflow Models)}

In this category, the whole building is considered as one single zone. It assumes that the pressure at a reference level is uniform. Temperature and concentration are considered constants. This approach can be used in the case of dwelling houses without partitions (case where the inside doors are opened). The objective is to study the heat and mass transfer between the inside of the building and the outside. Examples of one-zone models are the Type 19 of TRNSYS and the code CODYBA (Roux, 1984). CODYBA, developed later in 1984, is a dynamic program based on network analysis technique, developed initially as a $\mathrm{PhD}$ thesis (Roux, 1984) and improved to be used for energy design and load calculation of office buildings. This program includes many interesting features, but is limited to relatively small buildings and not appropriate to study the energy savings or load calculation for high-rise buildings. This program has a rigid interface and does not have the same flexibility as other programs, described later in this study, such as TRNSYS, DOE, to study particular problems encountered in the design process. CODYBA has been used for education, research and development. Later on, Smith Schneider et al. (1995) developed strategies for solving the air flow and thermal problems in multi-room buildings. AIDA-Air infiltration Development Algorithm (Liddament, 1986) is a basic single-zone ventilation and infiltration procedure. Despite its simplicity, it is robust and incorporates most of the applicable physics. Later, Sherman (1998) developed a single-zone stack-dominated infiltration model. The most interesting of this study is the introduction of a parameter called "stack height", which 
contains all of the leakage distribution information necessary for estimating stack flows, thus freeing the model from specific assumptions (e.g., that the leakage is separable into evenly distributed floor, wall and ceiling components).

\subsection{Multi-Room Thermal Models}

In general, the multi-room models treat heat transfer and airflow between different zones of a building. Multiroom models do not treat the local phenomena within a room, such as stratification and warm and cold draft. In this category of models, a zone is, in general, a specific room or even a collection of rooms. The whole apartment unit in a residential high-rise building can be represented by a single zone to study the interaction between units (Herrlin, 1992). Usually, there is confusion in literature, in which "multi-room" models are designated to be "multi-zone" models.

The multi-room thermal models constitute the majority of existing programs that are used by A-E design firms, such as HOT2000 NRC, 1995, HOT2000, 2003, the different versions of DOE (DOE-1, DOE-2 (Winkelmann et al., 1993; Reilly et al., 1992) and PowerDOE), PowerDOE, VisualDOE, Type 56 of TRNSYS, eQUEST, EnergyPlus (Crawley et al., 2001; 2005). In particular, ESP-r is a multi-room model coupled with a CFD model, which make it one of the few multi-zone models used by the A-E design firms. Other new multi-zone models have been developed for underfloor heating systems (Megri and Yu, 2014) and for UFAD systems (Yu and Megri, 2011).

TRNSYS is a transient system simulation program with a modular structure that was designed, initially in the 70's of the last century at the Solar Energy Laboratory at the University of Wisconsin (Klein et al., 1976; 2000), to solve complex energy system problems by breaking the problem down into a series of smaller components. Components, called Types in TRNSYS, may be as simple as a pump or pipe or as complicated as a multi-room building model. The TRNSYS multi-room building model is called Type 56. The stand-alone preprocessor program assists in creating the building description and avoiding input errors. The building description file is then converted into the data files used by the Type 56 model. To create the model of the system to be simulated by TRNSYS (Klein et al., 1976; Klein, 1983; 2000; Klein et al., 2000), the types required in the model are put into a TRNSYS input file known as a deck. The input and output interconnections between types are also described in the deck. The deck contains the simulation parameters, such as start and stop times and convergence tolerances, as well as defining output of results. Since the 15 th version of TRNSYS all the input data, as well as all link between different types, are introduced using interface, such as IISIBAT (Keilholz, 1996).

Type 56 of TRNSYS does allow a different approach to calculate the energy usage of the building by using the energy rate control method without specifying the HVAC system type. The underlying assumption of this method is that the HVAC equipment is adequately sized to meet the load at all times (McDowell et al., 2003). When the internal loads and other gains and losses are calculated, Type 56 checks to see if the zone set-point has been maintained. If not, then the amount of energy required to maintain the set-point temperature independent of the HVAC system efficiencies and operating characteristics is determined. With this method, the latent loads are determined by maintaining a relative humidity set-point, but only when there is a corresponding sensible cooling load. Consequently, the TRNSYS loads are simply represented as the idealized energy to maintain set-point. The component loads can be very different from the energy required to meet the loads because they can incorporate system issues in the loads. For example, the heating coil load is not the heating load required if the system has reheat incorporated in the cooling system. This situation leads to a heating coil load appearing in the cooling season of the building, but not appearing in the energy rate control loads. Other factors that can lead to differences between the component load and the energy rate control total loads are the component efficiencies, the equipment being sized too small to meet the load, addition of fan heat, heat recovery (McDowell et al., 2003). ESP-r, also calculates building loads using idealized controls. As well, it is possible to calculate the energy consumption of HVAC equipment with the explicit plant modeling approach. The former is likely similar to the loads calculated with TRNSYS.

eQUEST provides a graphical user interface for the DOE-2.2 program (Winkelmann et al., 1993; Reilly et al., 1992), which uses the weighting factor method and uses a sequential approach that includes: Loads model, Systems and Plant models and also an Economic model. It is capable of modeling a wide range of commercial buildings and systems. The user interface and "wizards" make it the easiest of the multi-room programs to use. It is recommended for any building that does not require more advanced simulation features found in more sophisticated programs, such as DOE-2, EnergyPlus 
(Crawley et al., 2001) and ESP-r. DOE-2 and derivative programs such as PowerDOE and eQUEST use the building-system-plant approach for modeling building energy usage and have a stock set of HVAC system types. Consequently, the DOE2 loads are reported as HVAC system component loads (i.e., cooling coil, heating coil), which make it very interesting, since different systems uses different amounts of energy. For example, reheat systems apparently use more energy than variable-volume systems.

\subsection{Multi-Room Airflow and Contaminant Models}

There are two fundamental approaches to determine the airflow rate in buildings: Measurement and mathematical modeling (Liddament, 1996). In the multiroom approach, a building and its plant are treated as a collection of nodes representing rooms and HVAC system components, with inter-nodal connections representing the distributed flow paths associated with cracks, doors, windows, HVAC ducts, fans and the like. The network nodes represent the zones, each of which are modeled at a uniform temperature and pollutant concentration. The pressures vary hydrostatically, so the zone pressure values are constant only at a specific elevation within the zone. A simple, nonlinear relationship is assumed, such as the power law for cracks and the polynomial equation for fans, between the flow through a connection and the pressure difference across it. Pressure coefficients, relating the wind pressure at the building to the wind velocity, can be attributed to external nodes. Not only wind effect, but also buoyancy (stack effect) resulting from temperature and air composition differences are taken into account. Conservation of mass for the flows into and out of each node leads to a set of simultaneous, nonlinear equations which can be integrated over time to characterize the flow domain. The network of equations is then solved at each time step of the simulation.

The most interesting work that has been developed within the international community is the development of an evaluated multi-room airflow program Conjunction Of Multi-zone Infiltration Specialists (COMIS) within the framework of the International Energy Agency's Buildings and Community Systems Agreement, Annex 23 (Feustel and Rayner-Hooson, 1990; Megri, 1993). The COMIS project was supported between 1990 and 1996 by nine participating nations. COMIS is a multi-room air infiltration, ventilation and contaminant transport simulation program. Measured data from existing buildings from more than ten countries were used to check the simulation results
(Megri, 1993; Amara, 1993). User interfaces were developed to facilitate the use and to ease the dissemination of COMIS. Later, COMIS become a multi-zone model, after the integration of the zonal model within it (Ren, 2002), as well as the integration of COMIS with the thermal multi-room model of TRNSYS (Dorer and Weber, 1994; Megri, 1995). Despite the concerted efforts from the international community in terms of its development, evaluation and finally the integration of an intelligent interface ISSIBAT, COMIS is still relatively difficult to use. The program COMIS constitutes also the airflow part of EnegryPlus (Huang et al., 1999).

CONTAM (Walton, 1997; Walton and Dols, 2005) is a multi-room airflow and contaminant dispersal program that contains an updated version of the AIRNET model (Walton, 1988; 1989) and a graphical interface (Dols and Walton, 2002) for data input and display. The latest version of CONTAM is CONTAMW 3.1. Although CONTAM treats "the imaginary zones" as well as calculates the inter-zonal airflow, it is still not able to determine the distribution of airflow and temperature within the same room. Recently, CONTAM has been integrated to the Type 56 of TRNSYS.

Both COMIS and CONTAM combine the best available algorithms for modeling the airflow and contaminant transport in multi-room buildings (Allard et al., 1990; Rodriguez and Allard, 1992; Walton, 1988; 1989) with a graphical interface for entering the description of the building and all input data. The recent version of CONTAM includes a new contaminant solver (CVODE) and a new TRNSYS type. This new solver is a variable time step for transient contaminant transport calculations (NIST web page).

The CONTAM interface is more intuitive than the IISIBAT (Keilholz, 1996) interfaces of TRNSYS and COMIS, as it draws a detailed graphic showing the building zone and walls and then enters the airflow paths, other airflow elements and their mathematical characteristics. Fundamentally, there are no big differences between these two programs. A comprehensive validation of both COMIS and CONTAM has been carried out, in the framework of Annex 23 of the IEA, using inter-model comparison, field and laboratory experimentations (Haghighat et al., 1996). Emmerich (2001) addressed the issues of measurement uncertainty and statistical analyses of the comparison between measurements and predictions for multi-room IAQ modeling of residential buildings. Recently, Axley et al. (2005) introduced mechanical power balances for multi-room 
building airflow analysis, since the conventional methods of multi-room airflow analyses ignore mechanical energy conservation in forming the system equations governing building airflows.

\subsection{Integrated Multi-Room Airflow and Thermal Models (COMIS/TRNSYS or CONTAM/TRNSYS)}

Thermal building simulation models without an integrated airflow model are inadequate in most cases, since the impacts of inter-zonal, infiltration and ventilation rates on energy usage of buildings are considerable. Basically, the simulation involves a thermal energy balance model and a mass flow network model. The thermal energy model assumes mass flow rates. The mass flow network model assumes temperatures. The assumed mass flow rate in the thermal model should be "the same" as the mass flow rate calculated in the mass flow network for the same time-step. Two basic approaches for integrating or coupling a thermal model with an airflow model (Hensen, 1991) are described:

- Approach 1: The thermal model calculates temperatures based on assumed airflows, after which the airflow model recalculates the airflows using the calculated temperatures

- Approach 2: The airflow model calculates airflows based on assumed temperatures, after which the thermal model recalculates the temperatures using the calculated airflows

This means that either the temperatures (approach 2) or the airflows (approach 1) may be different in both models and steps need to be taken in order to ensure the thermodynamic integrity of the overall solution (Hensen, 1991). In other words, the values of thermodynamic variables such as temperature and mass flow rate should be equivalent across simulation models at any point over simulation time.

In the case where the thermal model and the airflow model are actually separate programs running in sequence, such as the airflow models COMIS and CONTAM and the thermal model DOE, the above procedure cannot be done on a per time step basis. This is the so-called sequential coupling as described by Kendrick (1993) and quantified with case study material by Heidt and Nayak (1994). For applications involving buoyancy driven airflow, called stack effect, the thermodynamic integrity of this type of coupling should be seriously questioned (Hensen, 1995). When using inter-model sequential coupling for those types of applications, relatively large errors in predicted temperatures and flows may be expected.

In the case where the thermal and airflow model are integrated in the same software system, the above procedure is possible for each time step and the thermodynamic integrity can be guarded by (Hensen, 1995):

- A de-coupled approach ("ping-pong" approach) in which the thermal and airflow models run in sequence (i.e., each model uses the results of the other model in the previous time step). The airflow calculations use air temperatures calculated in the previous time step. Obviously the other way around is also possible. In the ping-pong approach, each model uses input values calculated by the other model at the previous time step. For example, to calculate the airflows at hour " $\mathrm{t}+\Delta \mathrm{t}$ ", the airflow model uses zone temperatures calculated by the thermal model at hour $\mathrm{t}$ and

- A coupled approach (or "onion" approach) in which the thermal and flow models iterate within one time step until satisfactory small error estimates are achieved. In the onion approach, the airflow and thermal models iterate back and forth at each time step until the output values of both are within the acceptable tolerances

The ping-pong method may generate substantial errors, while the onion method may require substantially greater computing effort. Obviously, the final results in terms of evolution of the thermodynamic integrity, will depend on how fast boundary values and other external variables to the models change over time. Therefore, the length of the simulation time step is also an issue that needs to be considered. Examples of this category are: EnergyPlus/COMIS, Type 56 of TRNSYS /COMIS and Type 56 of TRNSYS/CONTAM. For the case of the integration with TRNSYS, at each time step of the simulation a solution is iteratively determined. In each iteration loop the room air temperature values are passed from the thermal building model Type 56 to COMIS Type or CONTAM Type, which returns the respective airflow rates to Type 56. The predicted airflow rates per room are assigned to inter-zonal, infiltration or ventilation, which all are required by Type 56 . The integrated program has been served to study extensively the "off-hour" ventilation in office buildings.

It is interesting to mention here that other approaches have been used. For instance, (Axley and Grot, 1989) 
uses another approach that consists of single equations describing air and heat flow, "full integration" (Kendrick, 1993). The reader also is referred to (Kelly, 1998; Beausoleil-Morrison, 2000).

\subsection{Integrated Multi-Room Thermal Model and Zonal Model}

Although the multi-room models have been proved to be acceptable for predicting energy consumption for building equipped with overhead ventilation systems, they are not appropriate to be used in a non-uniform environment created by other HVAC systems, such as the case of displacement ventilation and Under Floor Air Distribution (UFAD) systems (Schiavon et al., 2012). In the case of UFAD systems, a zone is separated by a raised floor into two spaces, the occupied zone space and the floor plenum space. Airflow from airconditioning units is delivered to the floor plenum and then supplied to the occupied space above through floor diffusers. Consequently, new energy prediction approaches based on the characteristics of these ventilation systems has been developed ( $\mathrm{Yu}$ and Megri, 2011; Megri and $\mathrm{Yu}, 2010$ ), in consideration of the limited applicability of the existing multi-room models in building energy prediction for these systems.

\section{CASE STUDIES AND DISCUSSION}

In this part, two case studies has been presented in which airflow (COMIS and CONTAM), thermal (Type 56 of TRNSYS) and integrated programs (COMIS/Type 56 of TRNSYS) have been used progressively to demonstrate the adequacy of each program to solve engineering design and analysis problems.

\subsection{Pollution Transport from Service Zones to Inhabitable Zones, using Airflow Multi- Room Modeling Approach (CONTAM and COMIS Programs)}

The overall objective of this study is to predict the pollutant dispersion of winter vehicle morning cold start exhaust and evening vehicle hot soak evaporative emissions between garage and house in residential buildings. The first step was to carry out an accurate characterization of the airflow characteristics using a minimum number of experimentation. Two set of blower doors test have been performed to determine flow coefficient $\mathrm{K}$ and flow exponent $\mathrm{n}$, from the power law, of the house and garage envelopes. $\mathrm{K}$ is an indication of the size of the opening and $\mathrm{n}$, is a measure of the flow type. They depend on the type of crack, material used and the quality of workmanship. However, detailed information about the distribution of cracks and gaps over the envelope of the building, such as the interface of window and door frame, ceiling/wall/floor interface, penetration of pipes, etc. are needed to run airflow programs, such as CONTAM and COMIS. The value of flow coefficient and flow exponent for the interface between the house and the garage were determined by mathematical manipulation that involves the subtraction of the airflows value from the two blower tests. For the characterization of different envelope components, it is, therefore, required that the global flow coefficient determined by blower door tests be distributed among cracks and gaps. To distribute the leakage data, a number of assumptions were made and these assumptions have been verified by parametric studies.

Technical Note AIVC 44 (Orme et al., 1994) provides data on the lower quartile, median and the upper quartile of leakage values for components and fittings used in the construction of buildings. Therefore, it is assumed that the airflow paths (cracks and gaps) of the investigated buildings have similar characteristics as those given in the AIVC Technical Note 44, but not necessarily the same value. Assuming a universal flow exponent for the airflow paths, the flow coefficients for each airflow path, $\mathrm{i}$, is calculated by:

$$
\mathrm{K}_{\mathrm{i}}=\frac{\mathrm{K}_{\mathrm{i} \text { AIVC }} \cdot \mathrm{K}_{\text {measured }}}{\sum \mathrm{K}_{\mathrm{i}, \mathrm{AIVC}}}
$$

where, $\mathrm{K}_{\mathrm{i}, \mathrm{AIVC}}$ is the value of the flow coefficient for component, i, from the literature (Orme et al., 1994) and the $\mathrm{K}_{\text {measured }}$ is the measured global flow coefficient. In general, the median value of $\mathrm{K}$ was used except when "major" airflow path was observed during the smoke test. In this case, the upper quartile value given in the literature was considered. If no value for a component (i.e., type of window) was found in the literature, a $\mathrm{K}$ value was calculated considering the airflow path as an orifice. It was also assumed that the house envelope is insulated with air barrier and the $\mathrm{K}$ was distributed proportionally to the ceiling area of each room. It was also considered that the insert and damper of fireplace are closed. One of the main criteria of flow coefficient selection form literature was it must match the construction material and condition of the tested building such as the construction materials (concrete, timber or steel), the type of windows and doors (weather-stripped, unweather-stripped), penetrations (location of the 
installations), wall junctions. Some studies have shown that most of flow exponents for airflow paths at the material interfaces or joints are within \pm 0.12 of their mean value. Therefore, it is assumed that for a given unit (i.e., a house) the flow exponents for all airflow paths on the exterior walls are identical (Haghighat, 2003).

The cold start and hot soak experiments are performed according to very specific procedure. It is also assumed that there is a delay of five to six minutes in the air sampling in the garage and 8 to 9 minutes in the house. A complete description of building envelope, HVAC air handling system, temperature distribution, weather data, as well as the emission rates for all contaminants have been introduced within the airflow models.

The opening and closing of the garage door and the movement of the car causes that some of the contaminants generated by the car combustion, namely Acetylene and $\mathrm{CO}$, escape from the garage. Airflow models were used to predict the contaminants concentration level using the measured emission rates for these contaminants. The Fig. 1 shows $\mathrm{CO}$ and Acetylene concentration in laundry room as predicted by airflow models in case of Cold Start in the morning.

The Fig. 2 shows Benzene and 2 Methyl-Pen concentration level predicted by airflow models, in case of Hot Soak in the afternoon. In both situations, simulations show that there is a delay of approximately 30 minutes between the peak concentration in the garage and the peak concentration in laundry room and the concentration level in garage is almost 20 times more than the concentration in laundry room.

\subsection{The Study of the Efficiency Off-hour Ventilation in a Large Office Building with an Integrated Airflow and Thermal Model (COMIS/Type 56 of TRNSYS)}

During the night, the outdoor air temperature often drops below $20^{\circ} \mathrm{C}$, even during the summer. This cooling source can be used to reduce the energy consumption of the cooling system if the building is ventilated with a large amount of outdoor air during the night. In order to reduce the air conditioning system use and consequently, energy consumption, many studies have been conducted to improve the use of night accelerated ventilation using thermal model (Blondeau et al., 1995).

In our case, an integrated model, Type 56 of TRNSYS/COMIS, has been used to estimate the savings in energy consumption when the off-hour and day accelerated ventilation technique is employed instead of the air conditioning system.

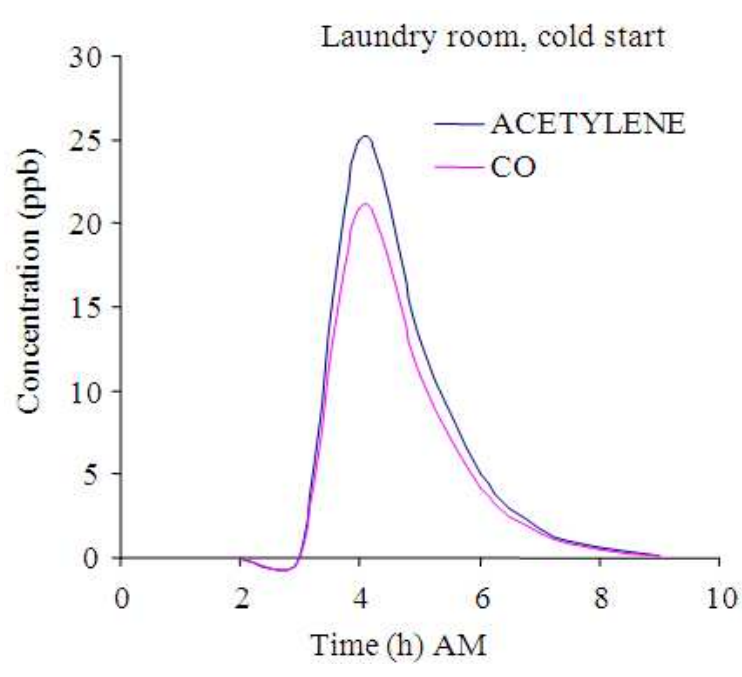

Fig. 1. Concentration of Acetylene and $\mathrm{CO}$ within the laundry room in case of cold start

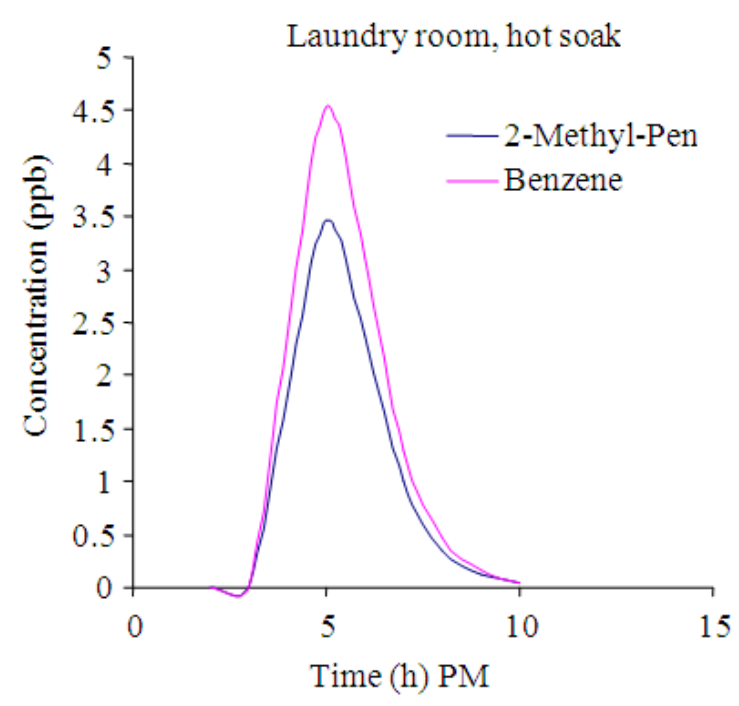

Fig. 2. Concentration of Benzene and 2-Methyl-Pen within the laundry room in case of hot Soak

The study is carried out on an office building with designed exhaust and exhaust/supply mechanical ventilation systems, as well as flow controllers. The building contains a ground floor and 8 subsequent stories and one higher floor under the roof. To simplify the study, one representative floor is considered for simulation taking into account the actual boundary conditions. Further, elementary zones with same orientation and similar operation are combined to make up only 8 representative thermostat control zones (Fig. 3). 


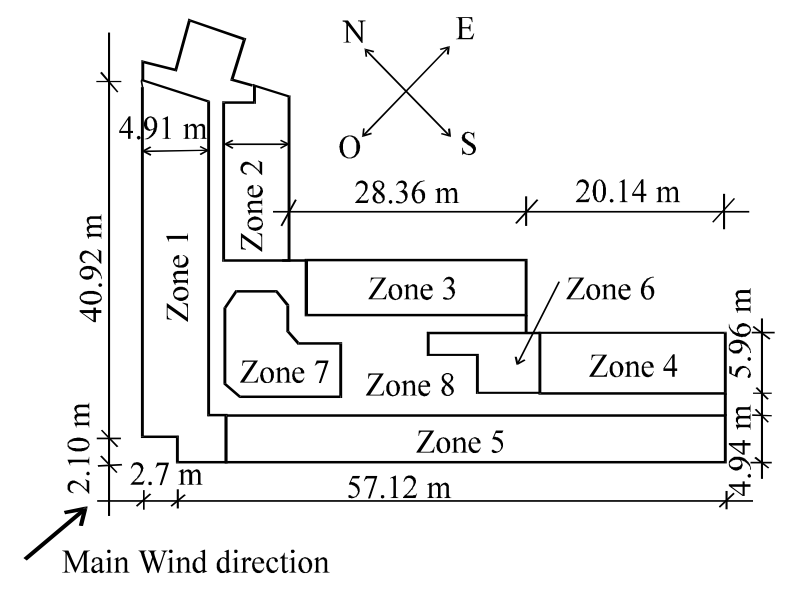

Fig. 3. Building used for the simulation

The fans have been characterized experimentally. Simulation was carried out using the meteorological data from the Carpentras commune in the Vaucluse department, in the Provence-Alpes-Cote d'Azur region in the southeastern France. The zones affected by the wind are zones 1 and 5 and from weather data, the wind velocity varies between 1.5 and $11.8 \mathrm{~m} \mathrm{~s}^{-1}$.

Because of the large airflow to be exhausted (or supplied), we consider separate ductwork and fans for each zone (7 fans and 7 networks), except for the hall (zone 8) whose air is exhausted via the bathroom exhaust. The ducts are designed for an exchange rate of $5[1 / \mathrm{h}]$ and the flow controllers are designed for an exchange rate of $10[1 / \mathrm{h}]$. The air inlets are located at the facades of the perimeter offices. The air exchanges in the internal zones $(6,7$ and 8$)$ are provided by transfer grills. The air exhaust takes place in each office, toilet and the meeting room via return grills. Every office is equipped with: 1 outdoor air supply, 1 transfer grill and 1 return grill equipped with a damper. The only exception is one office in zone 1 (the office in the corner of zone 1) which is equipped with 2 inlet air grills, one in each facade. Every office has a crack in the external and internal walls, characterized by the power law $\left(\mathrm{K}=0.002 \mathrm{Kg} /\left(\mathrm{s} . \mathrm{Pa}^{\mathrm{n}}\right), \mathrm{n}=0.65\right)$.

The results from the comparison between the integrated model (coupled airflow/thermal model) and the thermal model show that the integrated model need be used, since large differences between the two models are observed. The differences in temperature " $\Delta \mathrm{T}$ " calculated by the two models are very significant in the zones exposed to the direct wind velocity. The thermal model may be over or under estimate the indoor temperature. As an example, the Fig. 4 shows the differences between the two models during a one week period.

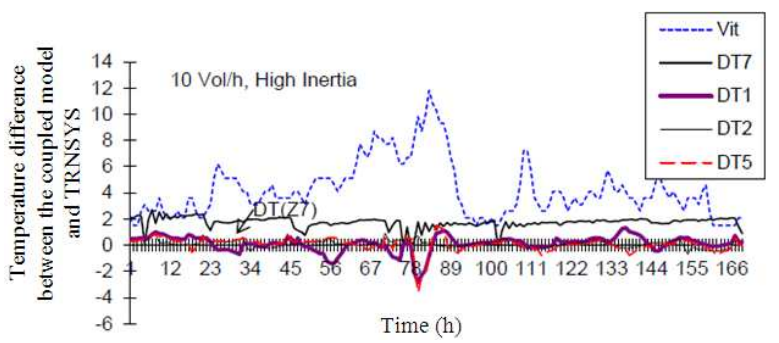

Fig. 4. Comparison between the Coupled and Thermal Models$10 \mathrm{vol} / \mathrm{h}$ (Vit indicates the wind velocity, DT1: difference of temperature, zone 1)

The thermal models assume that infiltration and ventilation are constants and the inter-zonal airflows are not considered. However, the airflow in a building changes significantly according to the weather conditions, the leakage characteristics of the walls and the operation of the ventilation system. This is especially true when accelerated ventilation is employed in a large building where the interaction between zones is high, which creates a very large inter-zonal airflow. Furthermore, the airflow components, in particular the envelope inlet air grilles, are designed differently to support large airflow.

\section{CONCLUSION}

The multi-room approach has been developed in the 70 's of the last century and continues to be used for energy analysis and design of HVAC systems for the majority of the Architectural Engineering projects. This approach has been for a long time considered as an intermediate method between the simplified "monozone" method and the detailed CFD approach. This situation is no longer valid with the introduction of "zonal" models. Recently, the zonal models have known a significant progression, in term of the development of new accurate models and also in term of application.

In this study, we presented two case studies where airflow, thermal or integrated modeling approaches are gradually used to predict the dispersion of pollution within residential buildings and to estimate the energy savings from off-hour accelerated ventilation within commercial buildings.

Regarding problems related to indoor pollution, airflow models have the potential to analyze the dispersion of contaminants, through cracks and permeable materials, from service zones to living zones with acceptable accuracy.

The comparison between thermal and integrated models shows the effect of natural ventilation on the 
efficiency of off-hour accelerated ventilation and the importance of using an integrated model over thermal model, because of the significance of the inter-zonal airflows. Consequently, the integrated approach is necessary to study the off-hour accelerated ventilation in commercial buildings, especially in order to establish the technological aspects in adapting the ventilation system (fan, duct, flow controllers) to be used for both night and day ventilation over a long period.

\section{REFERENCES}

Allard, F., V.B. Dorer, H.F. Feustel, E.R. Garcia and M. Grosso et al., 1990. TN 29: Fundamentals of the multizone airflow model-COMIS. Air Infiltration and Ventilation Centre, Coventry (UK).

Amara, F., 1993. Contribution à la caractérisation aéraulique des bâtiments. Etude de Transferts aérauliques dans les locaux multizones, Ph.D., Thesis, Lyon, France, INSA.

Axley, J. and R.A. Grot, 1989. The coupled airflow and thermal analysis problem in building airflow system simulation. Am. Society Heating, Refrigerating AirConditioning Eng. Trans., 95: 621-628.

Beausoleil-Morrison, I., 2000. The adaptive coupling of heat and air flow modelling within dynamic wholebuilding simulation. PhD., Thesis, University of Strathclyde, Glasgow UK.

Blondeau, P., M. Sperandio and F. Allard, 1995. Ventilation nocturne acceleree pour le rafraichissement des batiments en été.

Crawley, D.B., L.K. Lawrie, F. Winkelmann, W.F. Buhl and Y.J. Huang et al., 2001. EnergyPlus: Creating a new-generation building energy simulation program. Energy Build., 33: 319-331. DOI: 10.1016/S03787788(00)00114-6

Crawley, D.B., J.W. Hand, M. Kummert and B.T. Griffith, 2005. Contrasting the capabilities of building energy performance simulation programs. Proceedings of the 9th International IBPSA Conference, (IBPSA' 05), Montreal, Canada, pp: 231-238.

Diasty, R.E.L., P. Fazio and I. Budaiwi, 1993. The dynamic modelling of air humidity behaviour in a multi-zone space. Build. Environ., 28: 33-51. DOI: 10.1016/0360-1323(93)90004-M

Dols, W.S. and G.W. Walton, 2002. CONTAMW 2.0 User Manual. NISTIR 6921.

Dorer, V. and A. Weber, 1994, Multizone air flow model COMIS as type 57 for TRNSYS, IEA-ECB Annex 23 'Multizone Air Flow Modelling. Technical Note.
Emmerich, S.J., 2001. Validation of multizone IAQ modelling of residential-scale buildings: A review. National Institute of Standards and Technology.

Feustel, H.E. and A. Rayner-Hooson, 1990. COMIS Fundamentals. Lawrence Berkeley Laboratory.

Grundwald, J. and Y. Kikkawa, 2011. An integral building simulation method for evaluation of indoor climate applied to mold risk inside a library building. HVAC\&R Res., 17: 577-590. DOI: 10.1080/10789669.2011.594776

Haghighat, F. and H. Li, 2004. Building airflow movement-validation of three airflow models. J. Architectural Plann. Res., 21: 331-348.

Haghighat, F., 2003. Development of a procedure to evaluate the air leakage distribution from fan pressurization test-validation of three airflow models. Construction Informatics Digital Library.

Heidt, F.D. and J.K. Nayak, 1994. Estimation of air infiltration and building thermal performance. Air Infiltrat. Rev., 15: 12-16.

Hensen, J., 1995. Modeling coupled heat and air flow: Ping-pong vs. onions. Proceedings of the 16th Conference Implementing the Results of Ventilation Ressarch, (RVR' 96), AIVC, Coventry, UK, pp: 253-262.

Hensen, J., 1991. On the thermal interaction of building structure and heating and ventilation system. $\mathrm{PhD}$ Thesis, Technische Universiteit Eindhoven. Netherlands.

Herrlin, M.K., 1992. Air-flow studies in multizone buildings: Models and applications. Ph.D Thesis, Building Services Engineering, KTH, Stockholm, Sweden.

Huang, J., F. Winkelmann, F. Buhl and L. Berkeley, 1999. Linking the COMIS multi-zone airflow model with the energyplus building energy simulation program. Proc. Build. Simulat., 2: 1065-1070.

Haghighat, A., Y. Svitkin, I. Novoa, E. Kuechler and T. Skern et al., 1996. The eIF4G-eIF4E complex is the target for direct cleavage by the rhinovirus $2 \mathrm{~A}$ proteinase. J. Virol., 70: 8444-8450.

Keilholz, W., 1996. Développement d'un outil de calcul intégré multi-domaine, basé sur une approche orientée objets. Université Nice Sophia Antipolis, CSTB, Janvier.

Kelly, N.J., 1998. Towards a design environment for building-integrated energy systems: The integration of electrical power flow modelling with building simulation. Ph.D. Thesis, Department of Mechanical Engineering, University of Strathclyde. 
Kendrick, J., 1993. An Overview of Combined Modeling of Heat Transport and Air Movement. 1st Edn., Air Infiltration and Ventilation Centre, Coventry UK, ISBN-10: 0946075700, pp: 47.

Klein, S.A., 1983. TRNSYS, a transient system simulation program. Solar Energy Laboratory, University of Wisconsin-Madison.

Klein, S.A., B. Beckmann and J. Duffie, 2000. TRNSYS, A transient system simulation program. Solar Laboratory, Madison, Wisconsin.

Klein, S.A., W.A. Beckman and J.A. Duffie, 1976. TRNSYS-a transient simulation program. ASHRAE Trans.

Klein, S., 2000. TRNSYS-A transient system simulation program. Solar Energy Laboratory, University of Wisconsin-Madison.

Liddament, M., 1986. Air Infiltration Calculation Techniques: An Applications Guide. 1st Edn., Air Infiltration and Ventilation Centre, Bracknell, U.K, Bracknell, ISBN-10: 0946075255, pp: 220.

Liddament, M.W., 1996. A guide to energy efficient ventilation. 1st Edn., Air Infiltration and Ventilation Centre, Bracknell, U.K, ISBN-10: 0946075859, pp: 254.

Liddament, M.W., 1994. Simulation techniques for ventilation and airflow prediction. Proceedings of the European Conference in Lyon, (ECL' 94), pp: 214-219.

Majali, V., B.N. Prasad and A.K. Bhat, 2005. Development of an analytical tool in modeling of non-air-conditioned multi-zone buildings. J. Institution Eng. Ind. Architectural Eng. Division, 86: $15-19$.

McDowell, T.P., S. Emmerich, J.W. Thornton and G. Walton, 2003. Integration of airflow and energy Simulation using CONTAM and TRNSYS. ASHRAE Trans., 109: 1-14.

Megri, A.C., 1995. Prediction and evaluation of indoor air quality in multi-zone buildings equipped with a ventilation system. Série Equipement Technique, 119: 114-131.

Megri, A.C., 1993. Air flow modeling in multizone buildings equipped with a ventilation system: Prediction of pollutant transport. Ph.D. Thesis, INSA "National Institute of Applied Science, Lyon, France, Thermal Engineering Centre, Department of Civil Engineering and Building.

Megri, A.C. and Y. Yu, 2010. New calibrated zonal model for temperature, pressure and airflow predictions. Proceedings of the 10th REHVA World Congress Sustainable Energy Use in Buildings, May 9-12, Antalya, Turkey.
Megri, A.C. and Y. Yu, 2014. Energy prediction of electric floor radiation systems using a new integrated modeling approach. ASHRAE Trans.

Megri, A.C., C. Béghein and P.S. Schneider, 1996. Des logiciels de conception, d'analyse et de prédiction utilisés en thermique du bâtiment. Porceedings of the 3rd Canadian Conference on Computing in Civil and Building Engineering, (CBE' 96) Montreal, pp: 44-61.

Reilly, M.S., F.C. Winkelmann, D.K. Arasteh and W.L. Carroll, 1992. Modeling windows in DOE2.1E. Proceedings of the Conferene on Thermal Performance of the Exterior Envelopes of Buildings, Dec. 7-10, Clearwater, FL, pp: 1-19.

Ren, Z., 1992. Enhanced modelling of indoor air flows, temperatures, pollutant emission and dispersion by nesting sub-zones within a multizone model. PhD. Thesis, Queen's University of Belfast.

Rodriguez, E.A. and F. Allard, 1992. Coupling COMIS airflow model with other transfer phenomena. Energy Build., 18: 147-157. DOI: 10.1016/03787788(92)90043-G

Roux, J.J., 1984. Proposition de modèles simplifies pour l'étude du comportement thermique des bâtiments. Ph.D. Thèse, Institut National des Sciences Appliquées de Lyon.

Sherman, M., 1998. Single-zone stack-dominated infiltration modeling.

Smith Schneider, P., J.J. Roux and J. Brau, 1995. Strategies for solving the air flow-Thermal problem in multi-room buildings. Build. Environ., 30: 277286. DOI: 10.1016/0360-1323(94)00042-Q

Schiavon, M., M. Pittarelloa, E.A.H. Pilon-Smitsb, M. Wirtzc and R. Hellc et al., 2012. Selenate and molybdate alter sulfate transport and assimilation in Brassica juncea L. Czern.: Implications for phytoremediation. Environ. Exp. Botany, 75: 41-51. DOI: 10.1016/j.envexpbot.2011.08.016

Walton, G.N., 1988. Airflow network models for element-based building airflow modeling. National Institute of Standards and Technology, Gaithersburg, USA.

Walton, G., 1989. AIRNET: A Computer Program for Building Airflow Network Modeling. 1st Edn., National Institute of Standards and Technology, Gaithersburg, pp: 77.

Walton, G.N., 1997. CONTAM96 User Manual. 1st Edn., National Institute of Standards and Technology. pp: 66. 
Walton, G.N. and W.S. Dols, 2005. CONTAM 2.4 user guide and program documentation. National Institute of Standards and Technology.

Winkelmann, F., B.E. Birdsall, W.F. Buhl, K.L. Elllington and A.E. Erdem et al., 1993. DOE-2 Supplement. Lawrence Berkeley National Laboratory.

Yang, L., P. Xu and Y. Li, 2006. Nonlinear dynamic analysis of natural ventilation in a two-zone building part a-theoretical analysis. HVAC\&R, 12: 231-255. DOI: $10.1080 / 10789669.2006 .10391177$
Yu, Y. and A.C. Megri, 2011. Development and application of a new dynamic zonal model (POMA+). Proceedings of the 12th International Conference on Air Distribution in Rooms, Jun. 19-22, Trondheim, Norway.

Orme, M., M. Liddament and A. Wilson, 1994. An analysis and data summary of the AIVC's numerical Database. Air Infiltrationand Ventilation Centre, Coventry. 